\title{
The identification of Malaysian driving styles using the multidimensional driving style inventory
}

\author{
Juffrizal Karjanto ${ }^{1,2, *}$, Nidzamuddin Md. Yusof ${ }^{1,2}$, Jacques Terken ${ }^{1}$, Muhammad Zahir \\ Hassan $^{1,3}$, Frank Delbressine ${ }^{1}$, Hanneke Hooft van Huysduynen ${ }^{1}$, and Matthias Rauterberg ${ }^{1}$ \\ ${ }^{1}$ Department of Industrial Design, Eindhoven University of Technology, Eindhoven, The Netherlands \\ ${ }^{2}$ Faculty of Mechanical Engineering, Universiti Teknikal Malaysia Melaka, Melaka, Malaysia \\ ${ }^{3}$ Faculty of Engineering Technology, Universiti Teknikal Malaysia Melaka, Melaka, Malaysia
}

\begin{abstract}
A study was conducted to investigate the driving styles within the geographical region of Malaysia. The first part of the study determined Malaysian drivers' driving styles using the Multidimensional Driving Style Inventory approach. Respondents had various backgrounds in terms of age, gender and experience of driving. A statistical factor analysis was done for 338 respondents revealing four driving styles; careful, risky, anxiousdissociative and angry. In addition, a comparison with previous findings from Netherlands and Israel was also done in this study. The next part of the study focused on the associations of these driving styles with two personality traits (sensation seeking and desire for control), sociodemographic factors and experience of driving. The last part of the paper discusses the relevance of the study against the background of future automotive development.
\end{abstract}

\section{Introduction}

In Malaysia, the number of road accidents is steadily increasing while deaths remain static every year (Fig. 1). Although motorcycles are the number one contributor in accident fatalities in Malaysia, most of the accidents involve the motorcycle and passenger car [1]. Safety measures, like for example the implementation of Automated Enforcement System (AES) cameras which are able to identify drivers who are driving over the designated speed limit or running over the red light [2], were designed to penalize drivers by producing summons. Campaigns through media such as advocacy programmes are other initiatives to increase road safety awareness educate drivers, especially during festive season [3]. Generally, these kinds of safety measures are believed to create a safer driving environment and also helping in decreasing the accident rates in Malaysia.

On the other hand, researchers reported that sociodemographic factors and personalities are directly influencing the increment in the number of traffic violations and road accidents [4]-[6]. According to Risk Homeostasis Theory (RTH) developed by Wilde [7], drivers

\footnotetext{
*Corresponding author: j.karjanto@tue.nl
} 
will usually weigh the cost and benefits of alternate actions, thus they will accept certain level of risk which they actively target (target risk). As an example, running late for an interview could be compensated by speeding up as one will gain more time although it would cost the driver of getting a speeding ticket and higher chances of getting into traffic accident. Furthermore, according to the driver models by Näätänen and Summala [8], Summala [9], and Vaa [10], human driver drives a car in a satisficing manner where emotions are the strong driven factors. They elaborated that some drivers like the sensations out of speed, acceleration, driving with very close distance to the preceding vehicle and being competitive on the roads. In addition, some drivers are driven by motivations like social pressure and the need for control.

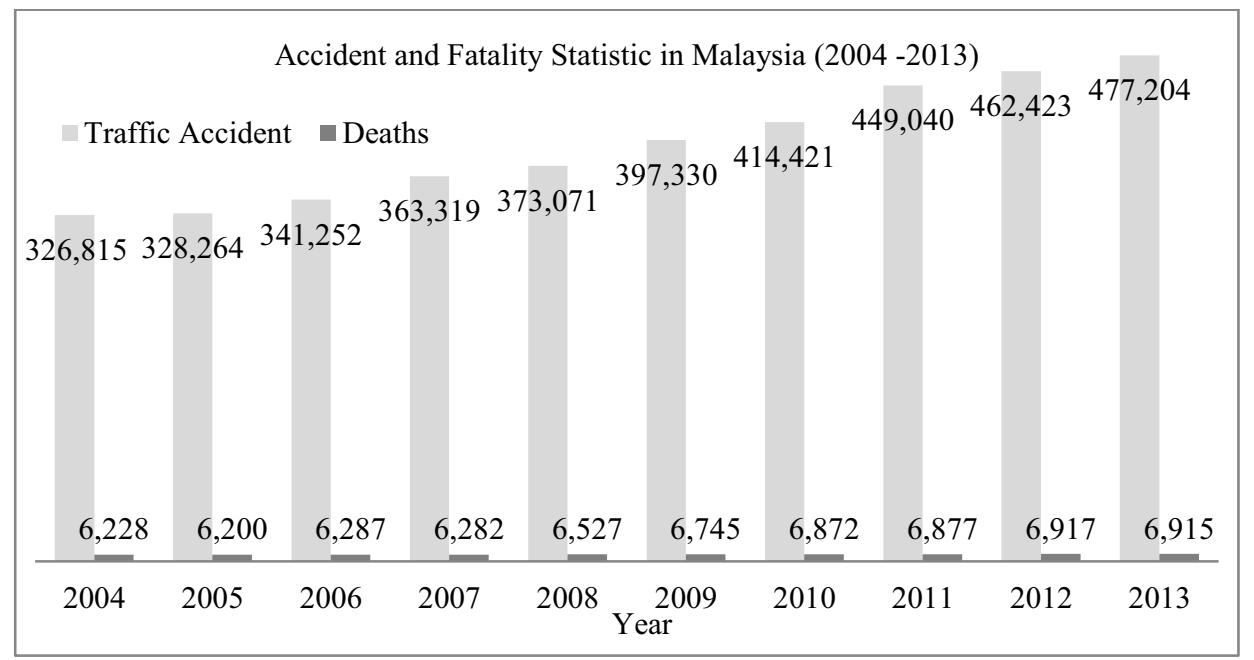

Fig. 1. Trends in reported road traffic accident in Malaysia [11].

Personality is a characteristic of individuals and concerns traits such as desire for control and sensation seeking. In the context of driving, the desire for control is one element of the control motive concept, which can lead a driver to adopt a careful driving behaviour, or a dangerous driving behaviour if the driver is in frustrated [12]. According to Dahlen et al. [13], a driver with a high sensation seeking trait likes to drive at or above the designated speed limit. This driving behaviour was reported to be the main culprit in traffic accidents [14], [15].

Taubman-Ben-Ari et al. [12] reviewed the existing scales of driving styles and believed that all these scales and definitions of driving styles can be integrated into one multidimensional concept of driving styles. They hypothesized that the existing scales of driving styles can be clustered into four general groups: reckless and careless driving style (e.g.[16]), anxious driving style (e.g. [17]), angry and hostile driving style (e.g.[14]), and patient and careful driving style (e.g.[16]). Based on their findings, they developed the Multidimensional Driving Style Inventory (MDSI) technique to assess the driving style of drivers. Originally, 80 items were used in a pilot sample in Israel, and 44 items remained as the final version of MSDI after the exploratory factor analyses were applied. This 44 itemsquestionnaire revealed eight clear and meaningful driving styles in Israel, which are: dissociative, anxious, risky, angry, high velocity, distress-reduction, careful and patient. Hooft van Huysduynen et al. [18] validated the developed MDSI technique by assessing the driving styles and driver profiles focussing on the drivers in the Netherlands and Belgium. Five out of the original eight factors were identified, and 36 items appeared to be stable compared to the 44 items from the original study by Taubman-Ben-Ari et al. 
Therefore, in order to understand the behaviours of the drivers on the road, there is a need to study driving styles among Malaysians. Driving style denotes typical driving behaviour that includes the operational control of the vehicle's speed, tactical skills such as overtaking another vehicle, and strategic behaviour such as speeding, and that may result in traffic violations [19]. Driving itself is a complex activity that includes the interaction of personality, motivational, emotional and social factors in a dynamic environment [20]. The aim of the study presented in this paper was to define Malaysian driving styles and their relation to two personality traits which are sensation seeking and desire for control. The MDSI technique was implemented to determine the Malaysian respondents' driving style(s) and statistical analyses were applied to determine the relation with gender, age, and experience. The findings of this study will help the automotive engineers to produce the next generation of vehicles that meet the Malaysian users' level of driving pleasure and comfort. In addition, the same understanding can also be used in tackling the road accidents issue as the identification of driving styles could provide a better platform for the road safety campaigns and accident prevention measures.

\section{Methodology}

\subsection{Procedures}

A set of questionnaires was distributed through email to individuals, academic institutes, and several government and private sectors in Malaysia. In addition, the questionnaires were also circulated to several Malaysian groups in Facebook. Respondents were asked to complete a set of questionnaires which comprised of sociodemographic background questions (such as age and gender), driving experience (such as period of having the driver's license, distance of driving in a year according to the scale developed by Lajunen, Corry, Summala and Hartley [21]), the revised MDSI driving styles assessment from Hooft van Huysduynen et al. [18], the Sensation Seeking questionnaire from Zuckerman, Michael Kuhlman, Joireman and Kraft [22], and the Desire for Control questionnaire from Burger and Cooper [23].

The Driving Style questionnaire was adapted from the MSDI (44 items) by TaubmanBen-Ari et al. [12] for Israeli drivers by Hooft van Huysduynen et al. [18], validating the MDSI for drivers in the Netherlands and proposing a questionnaire of 36 items. Participants were asked to rate each item on a seven-point scale (from "not at all" to "very much") expressing their feelings, opinions, and behaviour when driving on an average road trip.

The Sensation Seeking questionnaire developed by Zuckerman et al. [22] consists of 19 items. Response options for the items are "true" or "false. For a "yes" response, 1 point is scored. The points are summed to produce the final score (between 0 and 19). The "Desire for Control" questionnaire was developed by Burger and Cooper [23] and consists of 20 items on a seven-point scale (from "does not apply at all" to "always applies to me"). The scoring method is to average all the result with the exception that the scores for items 7,10 , 16, 19 and 20 should be inverted before summing all the scores. The methodological approach used in this study is shown in Fig. 2. 


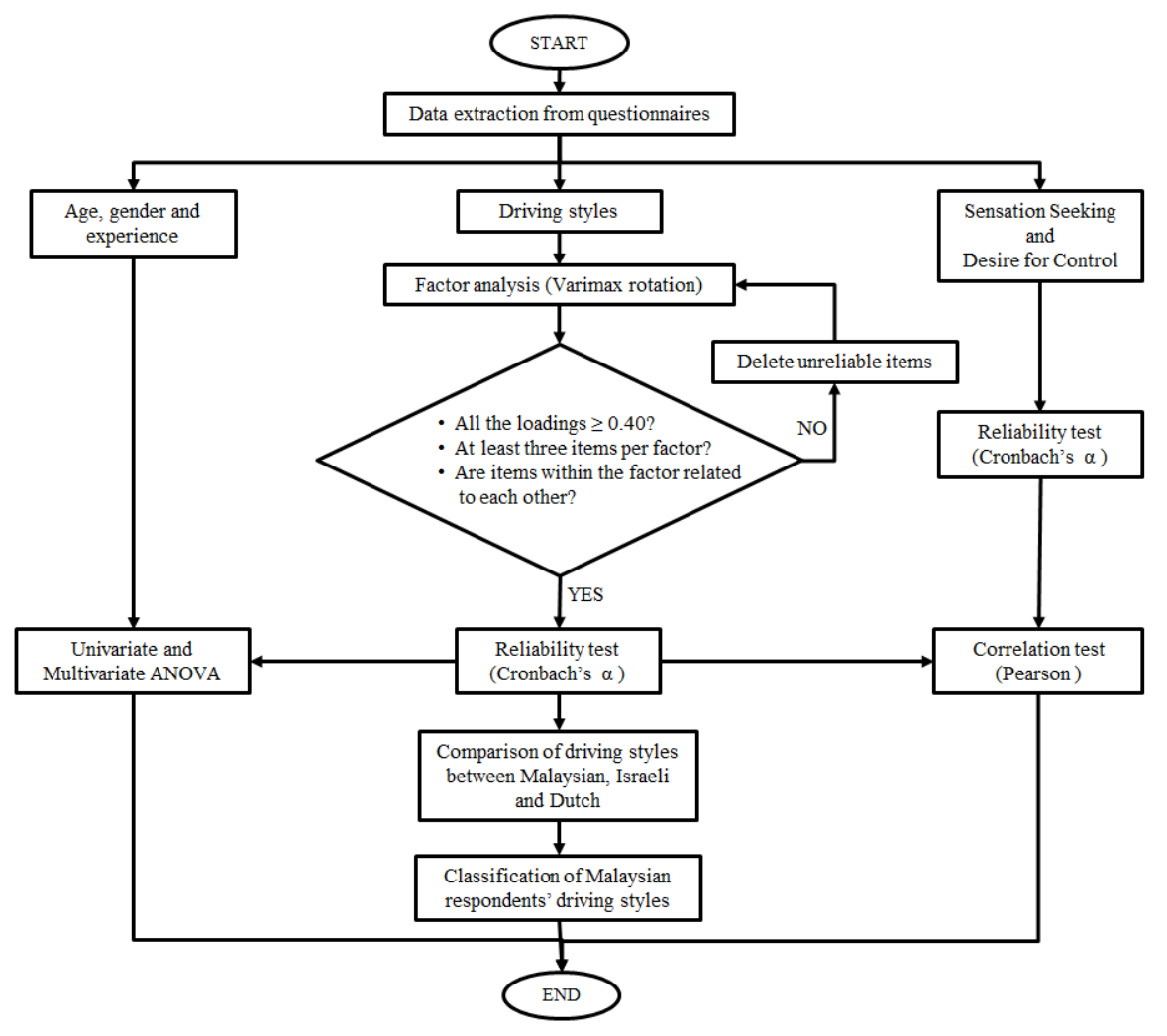

Fig. 2. Methodological approach used in the current study.

\subsection{Participants}

Three hundred and thirty eight (338) participants, who owned driving licenses, from various backgrounds (from university students, public servants to private sector workers) volunteered to participate is this study and completed the questionnaires through an online survey. The sample consists of $273(80.80 \%)$ men and $65(19.20 \%)$ women, ranging from the age of 20 to 66 years old (mean $(M)=28.00$, standard deviation $(\mathrm{SD})=7.07)$. In terms of driving experience, the number varies from 1 to 47 years of owning a driving license (M $=9.11, \mathrm{SD}=6.77$ ). In terms of type of driver, drivers with moderate experience (owning a driving license between 3 to 7 years) and experienced drivers (owning a driving license for more than 7 years) dominated the sample with $158(46.75 \%)$ and $157(46.45 \%)$ respondents, respectively, while the novice (owning a driving license for less than 3 years) drivers contributed to only $6.80 \%$ of the total respondents with 23 drivers.

\section{Results and discussion}

In this section, first the reliability of the Sensation Seeking questionnaire and the Desire for Control questionnaire will be considered, next, the factor analysis for the MDSI items for the Malaysian sample will be presented and the resulting MDSI questionnaire will be compared with those emerging from to the studies with Israeli and Dutch drivers. Then, the distribution of driving styles for Malaysian drivers will be presented. Finally, the relation with the sociodemographic factors (gender, age and experience) will be considered. 


\subsection{Internal consistency}

Cronbach's $\alpha$ was used to assess the internal consistency of the Sensation Seeking questionnaire and the Desire for Control questionnaire. According to Field in 2009 [24], a value of 1 indicates excellent reliability, while a value of 0.7 shows good reliability and a value that is lower than 0.3 is considered unacceptable. Cronbach's $\alpha$ for the Sensation Seeking questionnaire was good (0.78). Therefore, the responses of all items were added up into a single score and anyone who received a score between 11 and 19 was labelled as sensation seeker. Cronbach's $\alpha$ for the Desire for Control was also good (0.77). A higher average score for a respondent indicates a higher desire for control.

\subsection{The MDSI factors structure for Malaysian data}

A factor analysis using Varimax rotation was conducted, and six factors were set as the number of fixed factors based on the six factors found in the work of Hooft van Huysduynen et al. [18]. The Kaiser-Meyer-Olkin (KMO) measure of sampling adequacy revealed a value of 0.85 which indicates a significant adequacy as a minimum value of 0.50 is usually required [25].

For the first Varimax factor analysis, there are two requirements to look at in order to filter the items in each factor. First, all the factor loadings for each of the item have to be above 0.40 [12] and secondly, at least three items are required for each of the factors for there to be any meaningful contribution [26]. Based on the first requirement, items 7, 20, 21 and 28 were excluded from the second analysis because of the low factor loadings with a value of $0.39,0.35,0.31$ and 0.37 , respectively. Additionally, by the second requirement, factor 6 was dropped since it has only two items (item 11 and 5) and, therefore, would not contribute to any significant interpretation.

From the second analysis, all the factor loadings for all the items revealed values of above 0.40. Again, in the second analysis, the requirement for each factor was, at least three items per factor and, therefore, factor 5 was omitted for the next analysis since it had only two items (items 11 and 5). Next, in each of the factors, each of the items was scrutinized with respect to its relationship with the other items to see if there are meaningful contributions towards the formulation of driving styles. The items in factor 1 were related to cautious and vigilant driving and therefore, factor 1 was labelled as "Careful" driving style for Malaysian drivers. However, item 1 and 30 did not relate coherently with the other items in factor 1 since they related to relaxing activities in driving and consequently were heterogeneous in a sense. Hence, for the third and final analysis, these two items were omitted. Factor 2 consisted of items containing words like "dangerous", "risk", "thrill" and "tailgate". Therefore, factor 2 was labelled as "Risky" driving style. In this factor, all the items were related with each other, and there was no omission of an item required.

The items in the next factor, factor 3 , linked to the nervousness, distress and frustration of the driver while driving and, in addition, there were also elements like misjudged, forgetful and clumsiness. Thus, this factor was labelled as "Anxious-Dissociative" driving style. This hybrid and new driving style (the combination of two driving styles from the previous studies) will be further discussed in the next subchapter. Within this factor, item 15 was not included in the final analysis since this item was not related with the other items. In factor 4, all of the items noticeably show the driver's heated tendency toward other drivers. The kind of treatment to fellow drivers such as honking, swearing and flashing lights specified this factor as "Angry" driving style. One of the items in factor 4, item 16, was related to distraction and absent-mindedness and clearly did not relate to angry driving and, therefore, was dropped for the final analysis. 
Since some items needed to be dropped after the second analysis, a final and third analysis was done to recheck the stability of each factor for the remaining items. For the third analysis, the items were pushed into four factors, and the final result of stabilized loading factors is shown in Table 1. The final scale was reduced to 24 items distributed across four factors. Next, the reliability of the scale was considered by looking at Cronbach's $\alpha$ for each of the factors as shown in Table 1. Examining the Cronbach's $\alpha$ value for factor 1 and 2 indicates good reliability $(0.80$ and 0.75 , respectively) while factor 3 and 4 has satisfactory reliability ( 0.60 and 0.48 , respectively) from a statistical point of view.

Table 1. Results from the final Varimax factor analysis.

\begin{tabular}{|c|c|c|}
\hline Factor & Item & $\begin{array}{c}\text { Final } \\
\text { Loading }\end{array}$ \\
\hline Factor 1 & Careful driving style & \\
\hline \multirow{6}{*}{$\begin{array}{l}\text { Cronbach's } \\
\alpha=\mathbf{0 . 8 0}\end{array}$} & [34] Tend to drive cautiously. & 0.76 \\
\hline & [33] Always ready to react to unexpected manoeuvres by other drivers. & 0.73 \\
\hline & [13] Drive cautiously. & 0.73 \\
\hline & [8] While driving, I try to relax myself. & 0.72 \\
\hline & [18] Base my behaviour on the motto "better safe than sorry". & 0.69 \\
\hline & [4] Feel I have control over driving. & 0.52 \\
\hline Factor 2 & Risky driving style & \\
\hline \multirow{6}{*}{$\begin{array}{l}\text { Cronbach's } \\
\alpha=\mathbf{0 . 7 5}\end{array}$} & [36] Enjoy the excitement of dangerous driving. & 0.78 \\
\hline & [17] Like to take risks while driving. & 0.70 \\
\hline & [19] Like the thrill of flirting with death or disaster. & 0.68 \\
\hline & [24] Get a thrill out of breaking the law. & 0.61 \\
\hline & [2] Purposely tailgate other drivers. & 0.60 \\
\hline & [6] Enjoy the sensation of driving on the limit. & 0.41 \\
\hline Factor 3 & Anxious-Dissociative driving style & \\
\hline \multirow{7}{*}{$\begin{array}{l}\text { Cronbach's } \\
\alpha=\mathbf{0 . 6 0}\end{array}$} & [25] Feel nervous while driving. & 0.71 \\
\hline & [9] Driving makes me feel frustrated. & 0.64 \\
\hline & [26] Feel distressed while driving. & 0.63 \\
\hline & [31] Nearly hit something due to misjudging my gap in a parking lot. & 0.59 \\
\hline & $\begin{array}{l}\text { [22] Forget that my lights are on full beam until flashed by another } \\
\text { motorist. }\end{array}$ & 0.58 \\
\hline & $\begin{array}{l}\text { [27] Intend to switch on the windscreen wipers, but switch on the lights } \\
\text { instead. }\end{array}$ & 0.53 \\
\hline & [32] Feel comfortable while driving. [-] & 0.32 \\
\hline Factor 4 & Angry driving style & \\
\hline \multirow{5}{*}{$\begin{array}{l}\text { Cronbach's } \\
\alpha=\mathbf{0 . 4 8}\end{array}$} & [35] Honk my horn at others. & 0.73 \\
\hline & $\begin{array}{l}\text { [14] When a traffic light turns green and the car in front of me doesn't } \\
\text { get going immediately, I try to urge the driver to move on. }\end{array}$ & 0.68 \\
\hline & $\begin{array}{l}\text { [3] Blow my horn or "flash" the car in front as a way of expressing } \\
\text { frustrations. }\end{array}$ & 0.59 \\
\hline & $\begin{array}{l}\text { [23] When someone does something on the road that annoys me, I } \\
\text { flash them with high beam. }\end{array}$ & 0.58 \\
\hline & $\begin{array}{l}\text { [12] When a traffic light turns green and the car in front of me doesn't } \\
\text { get going, I wait for a while until it moves. [-] }\end{array}$ & 0.44 \\
\hline
\end{tabular}

Note:

- [-] indicates negative correlation

- $\quad$ The italic items have been moved from the original factor to another factor after the final analysis. 


\subsection{Comparison with Netherlands and Israel findings}

The findings of this study were compared with the preceding and are shown in Table 2. In the current study, for factor 1 (careful), the main difference is the addition of items 8 and 4 in this study. Item 8 , which is about relaxing oneself while driving, could be understood variedly by the diverse participants from these three countries, as this item was grouped differently for each analysis. While both of the previous studies agreed that item 4, which deals with the feeling of control over driving, was factored under the anxious driving style with negative correlation, this study found that the item sorted into careful driving style. The Malaysian study indicates that "control" has a significant and positive relationship with a careful driving style, which involves the element of planning and preparation in driving as has been discussed and found in the work of Taubman-Ben-Ari et al. [12].

Table 2. Comparison between findings of current (Malaysia) and previous two studies (Israel and Netherlands/Belgium).

\begin{tabular}{|l|c|c|c|}
\hline Items & Current Study & $\begin{array}{c}\text { Taubman-Ben-Ari } \\
\text { et al. [12] }\end{array}$ & $\begin{array}{c}\text { Hooft van } \\
\text { Huysduynen et } \\
\text { al. [18] }\end{array}$ \\
\hline$[34]$ & Careful & Careful & Careful \\
\hline$[33]$ & Careful & Careful & Careful \\
\hline$[13]$ & Careful & Careful & Careful \\
\hline$[8]$ & Careful & Distress-Reduction & Anxious \\
\hline$[18]$ & Careful & Patient & Careful \\
\hline$[4]$ & Careful & Anxious [-] & Anxious [-] \\
\hline$[36]$ & Risky & Risky & Risky \\
\hline$[17]$ & Risky & Risky & Risky \\
\hline$[19]$ & Risky & Risky & Risky \\
\hline$[24]$ & Risky & Risky & Risky \\
\hline$[2]$ & Risky & High-velocity & Anxious \\
\hline$[6]$ & Risky & Risky & Risky \\
\hline$[25]$ & Anxious-Dissociative & Anxious & Anxious \\
\hline$[9]$ & Anxious-Dissociative & Anxious & Anxious \\
\hline$[26]$ & Anxious-Dissociative & Anxious & Anxious \\
\hline$[31]$ & Anxious-Dissociative & Dissociative & Dissociative \\
\hline$[22]$ & Anxious-Dissociative & Dissociative & Dissociative \\
\hline$[27]$ & Anxious-Dissociative & Dissociative & Dissociative \\
\hline$[32]$ & Anxious-Dissociative [- & Anxious [-] & Anxious [-] \\
\hline$[35]$ & ] & Angry & Angry \\
\hline$[14]$ & Angry & High-velocity & Angry \\
\hline$[3]$ & Angry & Angry & Angry \\
\hline$[23]$ & Angry & Angry & Angry \\
\hline$[12]$ & Angry & Angry [-] & Angry [-] \\
\hline & Angry [-] & & \\
\hline & & & \\
\hline & & & \\
\hline & & & \\
\hline & & & \\
\hline
\end{tabular}

For the "risky" driving style, this study reveals six items and all the items, except one item (item 2 - "purposely tailgate another driver"), are in agreement with the findings of the previous two studies. All the items in the risky factor consist of elements of dangerous, thrill and sensation, which are all related to risky behaviour in driving. According to Jonah et al. [27], driving too closely to others and tailgating other drivers are strongly considered as risky driving since they would easily lead to a collision.

Four of the items found in factor 3 are identical with the items found in the previous two studies under the anxious driving style. The next three items are also similar to the previous two studies and fall under the driving style of "dissociative". As mentioned by Miller and 
Taubman-Ben-Ari [28], Taubman-Ben-Ari et al. [12] in their study already reviewed the existing driving style scales and hypothesized that anxious and dissociative driving style can be clustered together. They claimed that drivers who show signs of anxiety and fear, might have less confidence in driving. Therefore, the drivers would tend to get easily distracted due to majorly focusing on the operational parts of the driving task and thus display dissociative driving behaviour.

For the fourth and last factor, the "angry" driving style, all the items are about expressing anger and irritation such as urging, honking and swearing, and relate to the treatment of fellow drivers. The current study revealed five items of which four items (items 35, 3, 23 and 32) are similar to the findings from the previous studies ([12], [18]). Only one item (item 14) is different from the finding of Taubman-Ben-Ari et al. [12], but in Hooft van Huysduynen et al. [18] item 10 was also classified under the "angry" driving style.

\subsection{Malaysian driving styles distribution}

Based on the results from the factor analysis, respondents were classified into their own driving styles based on the MDSI questionnaire which they have answered. In this study, there are three methods being presented in order to reveal the driving styles distributions among the respondents. The first two methods are non-refined approaches, known as Sum Scores by Factor and Weighted Sum Scores [29]. For the first method, the highest sum of raw scores determines the respondent's driving style. Each raw score is corresponding to their item loading which any raw score with a negative factor loading will be subtracted in the calculation. In addition, the score is averaging in each factor if the total items inside each factor are not equal. By using the highest sum of raw scores, the first method identified $321(95.0 \%)$ respondents as drivers with a careful driving style, as shown in Fig. 3. For the second method, before the average scores were calculated, the score for each item was multiplied by the respective factor loading. The highest scoring result calculated by using this method indicated 330 respondents as drivers with a careful driving style. Similar to the first method, this method showed very little discriminating power as $97.6 \%$ out of the total respondents were identified as drivers with a careful driving style.

The first two methods take into account only the highest score in order to determine a respondent's driving style while leaving the scores for the other factors out of consideration. In the third method, the relative positions of the scores within the sample were taken into consideration. For example, if the driver scored relatively high for angry driving style, compared to other drivers within the sample, he or she will be classified as a driver with an angry driving style, even if his or her raw score for other driving styles were higher. Therefore, the third method which included the adjusted factor loadings was applied in this study. The same method was used by Hooft van Huysduynen et al. [18] in determining the multi-dimensional driver profiles in Netherlands and also implemented by Shahab, Terken and Eggen [32] in determining the multi-dimensional driver's personal values in driving.

The third method falls under the refined approaches where generally it is more complicated than the non-refined approaches. They are usually implemented to increase the validity and to obtain the unbiased estimation of the true factor scores by standardizing the correlation between the item and the factor by including the adjusted factor loadings. The adjusted factor loadings (calculated using Bartlett's method) were multiplied with each of the item scores before the average calculation in each factor was done. After that, the mean score and the standard deviation of the four-factor scores were calculated. Then, factor scores for each of the respondents 'driving styles were checked if they were exceeded the specific threshold, which is the sum of the mean and the standard deviation. This method 
identified a total of $223(66.0 \%)$ respondents with one driving style, and the distributions of the driving styles are shown in Fig. . On the other hand, 115 respondents do not have any specific driving style due to the fact that their factor scores did not exceed any specific thresholds. Interestingly, by using the third method, it was identified that nobody has more than one driving style.

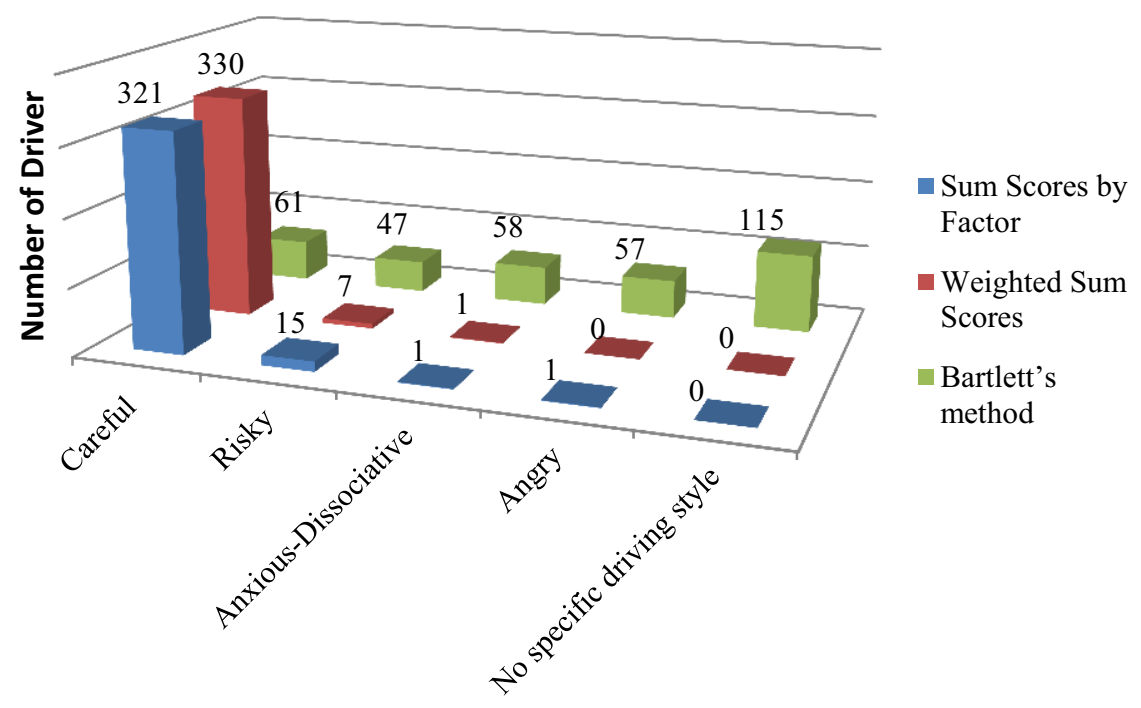

Fig. 3. Malaysian respondent's driving style determined using three different methods; sum scores by factor, weighted sum scores and Bartlett's method.

Table 3 shows the means and SDs of the raw scores for each factor for the 223 respondents with different driving styles. The columns correspond to the different driver types; the rows correspond to the Malaysian MDSI factors. As can be seen, all driver types have the highest score for careful driving, but the drivers with another driving style score relatively higher for their driving style in addition to scoring high for careful driving. This clearly demonstrates the challenge of how to assign driving styles in such a way that it gives sufficient discriminating power. The fact that they score high for careful driving as well can be understood by the fact that traffic is not a complete chaos.

Table 3. Tabulated of mean and standard deviation for Malaysian MDSI factors.

\begin{tabular}{|l|c|c|c|c|c|}
\hline \multicolumn{2}{|l|}{ Malaysian MDSI Factors } & Careful & Risky & $\begin{array}{c}\text { Anxious- } \\
\text { Dissociative }\end{array}$ & Angry \\
\hline \multirow{2}{*}{ Careful } & $\mathrm{M}$ & 5.98 & 2.21 & 2.59 & 3.24 \\
\cline { 2 - 6 } & $\mathrm{SD}$ & 0.99 & 1.51 & 1.88 & 2.05 \\
\hline \multirow{2}{*}{ Risky } & $\mathrm{M}$ & 4.65 & 4.02 & 2.88 & 3.46 \\
\cline { 2 - 6 } & $\mathrm{SD}$ & 0.96 & 1.20 & 1.59 & 1.64 \\
\hline \multirow{2}{*}{$\begin{array}{l}\text { Anxious- } \\
\text { Dissociative }\end{array}$} & $\mathrm{M}$ & 4.82 & 2.56 & 3.68 & 3.32 \\
\cline { 2 - 6 } Angry & $\mathrm{SD}$ & 1.03 & 1.13 & 1.26 & 1.48 \\
\cline { 2 - 6 } & $\mathrm{M}$ & 5.07 & 2.59 & 2.74 & 4.07 \\
\hline
\end{tabular}




\subsection{Personality traits and sociodemographic factors}

In addition to answering the MDSI questionnaire, the participants were also asked to fill in the Sensation Seeking questionnaire developed by Zuckerman et al. [22] and the Desire for Control questionnaire developed by Burger and Cooper [23]. The reason these two additional questionnaires were included was to investigate the correlations between driving styles and two personality traits (sensation seeking and desire for control). As stated in the literature, for example the recent work of Taubman-Ben-Ari and Yehiel [31] and Vaa [32], personality traits play an important role in determining the type of driver. Personality traits are hypothesized to be the root or the cause of why one is behaving in such way on the road. As mentioned by Vaa [32], personality traits can be viewed as dimensions of differences for any human in exhibiting their configurations of behaviour, emotions and cognition. Therefore, statistical analysis of Pearson correlations, as shown in Table below, were done to measure the relationship between the four factors (driving styles) found previously using the MDSI technique and the two personality traits of sensation seeking and desire for control. For Pearson correlations, a coefficient of +1 or -1 indicates perfect positive or negative correlations, while values of $+/-0.1$ represent a small effect, $+/-0.5$ represents a medium effect, and +/- 0.7 represents a large effect [24]. From Pearson correlation analyses, there are three relevant associations found, denoted by an asterisk $(\mathrm{P}<$ 0.01 , highly significant) as shown in Table 4.

Table 4. Pearson correlation coefficients between MDSI factors and personality traits.

\begin{tabular}{|l|c|c|}
\hline \multicolumn{1}{|c|}{ Malaysian MDSI factors } & Sensation Seeking & Desire for Control \\
\hline Careful & -0.05 & $0.40^{*}$ \\
\hline Risky & $0.40^{*}$ & -0.03 \\
\hline Anxious-Dissociative & -0.04 & $-0.24^{*}$ \\
\hline Angry & 0.08 & 0.13 \\
\hline${ }^{*} P<0.01$ & \multicolumn{2}{|c}{}
\end{tabular}

First, there is a positive and highly significant association between sensation seeking and risky driving style. As expected, risky driving is highly related to sensation seeking and this is shown by behaviours such as tailgating and driving over the limit. This correlation shows that drivers who score high for sensation seeking will have a higher tendency to be a risky driver. This result is in line with previous studies as reported by Taubman-Ben-Ari et al., [12] and Jonah [33] who also found a positive relationship between risky driving style and sensation seeking. In addition, sensation seeking is related to the opinion of the drivers about the acceleration forces experienced while driving as has been shown by the work of Lajunen and Summala [34], who found a positive correlation between sensation seeking and maximum speed and acceleration.

Second, the careful driving style has a highly positive correlation with desire for control. On the other hand, the anxious-dissociative driving style has a negative correlation with desire for control. These two correlations suggest that desire for control has a two-fold influence in driving; drivers with a high desire for control tend to be careful drivers and drivers with a low desire for control tend to be anxious-dissociative drivers.

Three MANOVA analyses were performed with the generated Malaysian MDSI factors and gender, age, and experience, to see if there are any significant effects between them. Indeed, these three elements showed significant associations as shown in Table 5.

Table 5. MANOVA for four Malaysian MDSI factors with gender, age, and experience.

\begin{tabular}{|l|l|l|l|}
\hline & \multicolumn{1}{|c|}{ Gender } & \multicolumn{1}{c|}{ Age } & \multicolumn{1}{c|}{ Experience } \\
\hline Malaysian MDSI & $\mathrm{F}(4,333)=4.089$, & $\mathrm{F}(8,664)=2.855$, & $\mathrm{F}(8,664)=2.480$, \\
factors & $\mathrm{p}<0.05(\mathrm{p}=0.003)$ & $\mathrm{p}<0.05(\mathrm{p}=0.004)$ & $\mathrm{p}<0.05(\mathrm{p}=0.012)$ \\
\hline
\end{tabular}


In order to check the significant fit of each the generated Malaysian MDSI factors and the two socio-demographic data (gender, age) and experience, univariate ANOVA was conducted for this study, as shown in Table 6.

Table 6. Mean, SD and univariate ANOVA of MDSI factors with gender, age, and experience.

\begin{tabular}{|c|c|c|c|c|c|c|c|c|}
\hline \multirow[b]{2}{*}{$\begin{array}{c}\text { Malaysian } \\
\text { MDSI } \\
\text { Factors }\end{array}$} & \multicolumn{2}{|c|}{ Gender } & \multicolumn{3}{|c|}{ Age } & \multicolumn{3}{|c|}{ Experience } \\
\hline & $\begin{array}{c}\text { Male } \\
(\mathrm{n}=\mathbf{2 7 3})\end{array}$ & $\begin{array}{c}\text { Female } \\
(n=65)\end{array}$ & \begin{tabular}{|l|} 
Young \\
$(\mathrm{n}=294)$
\end{tabular} & $\begin{array}{c}\text { Middle- } \\
\text { Aged } \\
(\mathrm{n}=42)\end{array}$ & $\begin{array}{c}\text { Elderly } \\
(n=2)\end{array}$ & $\begin{array}{c}<3 \\
\text { years } \\
(\mathrm{n}=158)\end{array}$ & $\begin{array}{c}3 \text { to } 7 \\
\text { years } \\
(n=23)\end{array}$ & $\begin{array}{c}>7 \\
\text { years } \\
(\mathrm{n}=157)\end{array}$ \\
\hline \multicolumn{9}{|c|}{ Careful driving style } \\
\hline Mean & 5.11 & 4.84 & 5.01 & 5.35 & 5.42 & 4.59 & 5.02 & 5.16 \\
\hline SD & 1.39 & 1.41 & 1.38 & 1.50 & 1.06 & 1.47 & 1.39 & 1.37 \\
\hline ANOVA & \multicolumn{2}{|c|}{$\begin{array}{c}\mathrm{F}(1,336)=3.014 \\
\mathrm{p} \geq 0.05, \eta_{\mathrm{p}}^{2}=0.031\end{array}$} & \multicolumn{3}{|c|}{$\begin{array}{c}F(2,335)=1.754 \\
p \geq 0.05, \eta_{p}^{2}=0.010\end{array}$} & \multicolumn{3}{|c|}{$\begin{array}{c}\mathrm{F}(2,335)=3.381 \\
\mathrm{p}<0.05^{*}, \eta_{\mathrm{p}}^{2}=0.020\end{array}$} \\
\hline \multicolumn{9}{|c|}{ Risky driving style } \\
\hline Mean & 2.88 & 2.63 & 2.91 & 2.34 & 2.42 & 2.89 & 2.95 & 2.70 \\
\hline SD & 1.51 & 1.53 & 1.51 & 1.45 & 0.82 & 1.46 & 1.52 & 1.50 \\
\hline ANOVA & \multicolumn{2}{|c|}{$\begin{array}{c}\mathrm{F}(1,336)=2.281 \\
\mathrm{p} \geq 0.05, \eta_{\mathrm{p}}^{2}=0.007\end{array}$} & \multicolumn{3}{|c|}{$\begin{array}{c}\mathrm{F}(2,335)=4.816 \\
\mathrm{p}<0.01^{* *}, \eta_{\mathrm{p}}{ }^{2}=0.028\end{array}$} & \multicolumn{3}{|c|}{$\begin{array}{c}\mathrm{F}(2,335)=1.451 \\
\mathrm{p} \geq 0.05, \eta_{\mathrm{p}}^{2}=0.009\end{array}$} \\
\hline \multicolumn{9}{|c|}{ Anxious-Dissociative driving style } \\
\hline Mean & 2.96 & 3.01 & 3.01 & 2.71 & 2.36 & 3.11 & 3.06 & 2.86 \\
\hline SD & 1.44 & 1.51 & 1.48 & 1.21 & 0.71 & 1.32 & 1.51 & 1.39 \\
\hline ANOVA & \multicolumn{2}{|c|}{$\begin{array}{c}F(1,336)=2.425 \\
p \geq 0.05, \eta_{p}^{2}=0.007\end{array}$} & \multicolumn{3}{|c|}{$\begin{array}{c}F(2,335)=2.413 \\
p \geq 0.05, \eta_{p}^{2}=0.014\end{array}$} & \multicolumn{3}{|c|}{$\begin{array}{c}\mathrm{F}(2,335)=4.769 \\
\mathrm{p}<0.01^{* *}, \eta_{\mathrm{p}}^{2}=0.028\end{array}$} \\
\hline \multicolumn{9}{|c|}{ Angry driving style } \\
\hline Mean & 3.57 & 3.25 & 3.55 & 3.26 & 2.20 & 3.47 & 3.55 & 3.48 \\
\hline SD & 1.66 & 1.64 & 1.66 & 1.61 & 1.13 & 1.60 & 1.70 & 1.63 \\
\hline ANOVA & \multicolumn{2}{|c|}{$\begin{array}{c}\mathrm{F}(1,336)=8.270 \\
\mathrm{p}<0.01^{* *}, \eta_{\mathrm{p}}^{2}=0.024\end{array}$} & \multicolumn{3}{|c|}{$\begin{array}{c}F(2,335)=2.255 \\
p \geq 0.05, \eta_{p}^{2}=0.013\end{array}$} & \multicolumn{3}{|c|}{$\begin{array}{c}F(2,335)=0.248 \\
p \geq 0.05, \eta_{p}{ }^{2}=0.001\end{array}$} \\
\hline
\end{tabular}

\footnotetext{
${ }^{*}$ indicates significant effect

${ }^{* *}$ indicates very significant effect
}

The univariate ANOVA revealed four important effects. Experience had a significant effect both on factor 1 (careful driving style, $F(2,335)=3.381, \mathrm{p}<0.05, \eta_{\mathrm{p}}{ }^{2}=0.010$ ) and factor 3 (anxious-dissociative, $F(2,335)=4.769, \mathrm{p}<0.01, \eta_{\mathrm{p}}{ }^{2}=0.028$ ). Analysing the mean values indicates that the experienced drivers $(>7$ years or driving experience) are more careful than drivers with moderate experience (between 3 to 7 years) and novice drivers $(<3$ years $)$ as it showed that the higher the experience gained, the more careful the driving style would become. By analysing the mean values for anxious-dissociative driving style, it is clearly indicated that higher experience drivers scored lower compared to less experienced drivers. In terms of age, the analysis of variance exposed a very significant negative effect associated with risky driving style with $\mathrm{F}(2,335)=4.816, \mathrm{P}<0.01, \eta_{\mathrm{p}}{ }^{2}=$ 0.028 . The younger drivers scored higher in risky driving style when compared to the older drivers. Angry driving style has a very significant dependency on gender $(\mathrm{F}(1,336)=$ $\left.8.270, \mathrm{P}<0.01, \eta_{\mathrm{p}}{ }^{2}=0.024\right)$ : male drivers have higher tendencies to have angry driving style compared to female drivers. This finding is in line with the work of Sullman, Stephens and Yong [35] who mentioned that male drivers in Malaysia are frequently showing their anger in driving compared to Malaysian female drivers.

\section{Conclusions}

In conclusion, based on this study, there are four major types of driving styles found from Malaysian drivers using the factor analysis method and MDSI questionnaire. The driving 
styles as revealed from the 338 respondents are careful, risky, anxious-dissociative and angry driving styles. By using Bartlett's method, 61 drivers (18.0\%), 47 drivers (13.9\%), 58 drivers $(17.2 \%)$ and 57 drivers $(16.9 \%)$ were identified as having a careful, risky, anxiousdissociative and angry driving style, respectively. The remaining 115 respondents $(34.0 \%)$ had no specific driving style. The comparison with the Israel and Netherlands studies did not reveal a lot of differences other than the former identified eight driving styles and the latter identified six driving styles while in this study four driving styles were found.

Pearson correlations and ANOVA (univariate and multivariate) analyses were conducted and associations between personality traits, socio-demographic factors, experience and driving styles were presented. In general, Malaysian drivers with a risky driving style were found to score high for sensation seeking trait was also influenced by age: younger drivers tend to exhibit more risky behaviour. For drivers with a careful driving style, experience plays a major role as it was found that longer experience will mould more careful drivers. Furthermore, Malaysian drivers with a high desire for control tend to have a careful driving style. For drivers with an anxious-dissociative driving style, a negative correlation was found with desire for control and also a significant relation with experience. For the angry driving style, there was a highly significant relation with gender where men were found to have higher associations with angry driving styles when compared to women.

This study provides knowledge about the relation between sociodemographic factors (age, gender and experience), personality traits and major Malaysian driving styles. The understanding, in particular, would contribute to better campaigns in providing awareness on human behaviour on the road. In addition, effective safety measures could be designed knowing that there are four major driving styles in Malaysia. Furthermore, when a driver's driving style can be established, engineers and designers could apply personalized persuasion in order to mitigate accidents and promote safe driving among the drivers. For example, a dashboard display that provides feedback by summarizing one's driving style over one trip or a system that automatically changes the colour of the dashboard into a more calming background might be devised by drivers with particular driving styles.

In the long run, the findings of this study may contribute to the development of the driving style of autonomous vehicles. The focus of development for future automobiles should not be put solely on the technology but also the behaviour or manners of the autonomous vehicle on the road [36]. It may be assumed that users of an autonomous vehicle who score high for sensation seeking will feel discomfort unless the induced forces in riding the autonomous vehicle are about the same as if they would drive themselves. Desire for control is crucial when a fully autonomous vehicle will be released to the market. It is projected that the vehicle will be without the manoeuvring controllers like pedals and steering as this operational task will be taken over by the autonomous vehicle. As mentioned by Dudley [37], who had the chance to experience riding in Google's autonomous vehicle, his first reaction was one of surprise by the absence of the controllers in the dashboard and he immediately felt the need for some sort of controls on the car. $\mathrm{He}$ mentioned that riding the Google fully autonomous vehicle was like riding in one of those amusement park rides where you have no control over the vehicle and just sit and go along with the ride.

The authors would like to express their gratitude and special acknowledgements to Universiti Teknikal Malaysia Melaka (UTeM) and Ministry of Education, Malaysia (KPM) for the funding of the Ph.D. programs of Juffrizal Karjanto and Nidzamuddin Md. Yusof and also the post-doctoral program of Muhammad Zahir Hassan in the Industrial Design Department, Eindhoven University of Technology, The Netherlands. 


\section{References}

1. M. M. Abdul Manan, A. Várhelyi, "Motorcycle fatalities in Malaysia," IATSS Res., vol. 36, no. 1, pp. 30-39, (2012)

2. S. Allyana, S. Mohamed, H. M. Jamil, M. Musa, N. Isah, W. S. Voon, "Impact Studies of Automated Enforcement System Implementation," (2014)

3. J. Mohd Marjan, N. Mohamed, M. R. Othman, F. Abas, F. Mohd Yusod, W. Shaw Voon, "Evaluation of the Effectiveness of OPS Bersepadu Hari Raya 2011," (2012)

4. D. J. Beirness, "Do we really drive as we live? The role of personality factors in road crashes," Alcohol, Drugs Driv., vol. 9, no. 3-4, pp. 129-143, (1993)

5. R. D. Garrity, J. Demick, "Relations among Personality Traits, Mood States, and Driving Behaviors," J. Adult Dev., vol. 8, no. 2, pp. 109-118, (2001)

6. M. J. M. Sullman, A. N. Stephens, M. Yong, "Driving anger in Malaysia," Accid. Anal. Prev., vol. 71, pp. 1-9, (2014)

7 G. J. Wilde, "The theory of risk homeostasis: Implications for safety and health," Risk Anal., vol. 2, no. 4, pp. 209-225, (1982)

8. R. Näätänen, H. Summala, "A model for the role of motivational factors in drivers' decision-making," Accid. Anal. Prev., vol. 6, no. 3-4, pp. 243-261, (1974)

9. H. Summala, "Towards understanding motivational and emotional factors in driver behaviour: Comfort through satisficing," in Modelling Driver Behaviour in Automotive Environments: Critical Issues in Driver Interactions with Intelligent Transport Systems, (2007), pp. 189-207

10. T. Vaa, "Modelling driver behaviour on basis of emotions and feelings: Intelligent transport systems and behavioural adaptations," in Modelling Driver Behaviour in Automotive Environments: Critical Issues in Driver Interactions with Intelligent Transport Systems, (2007), pp. 208-232

11. Malaysian Institute of Road Safety (MIROS), "Data Am Kemalangan Jalan Raya di Malaysia (1997 - 2014),” (2016). [Online]. Available: https://www.miros.gov.my/1/page.php?id=17. [Accessed: 16-Feb-2016]

12. O. Taubman-Ben-Ari, M. Mikulincer, O. Gillath, "The multidimensional driving style inventory - Scale construct and validation," Accid. Anal. Prev., vol. 36, no. 3, pp. 323332, (2004)

13. E. R. Dahlen, R. C. Martin, K. Ragan, and M. M. Kuhlman, "Driving anger, sensation seeking, impulsiveness, and boredom proneness in the prediction of unsafe driving," Accid. Anal. Prev., vol. 37, no. 2, pp. 341-348, (2005)

14. J. J. Arnett, D. Offer, and M. A. Fine, "Reckless driving in adolescence: 'State' and 'trait' factors," Accid. Anal. Prev., vol. 29, no. 1, pp. 57-63, (1997)

15. M. Zuckerman and M. Neeb, "Demographic influences in sensation seeking and expressions of sensation seeking in religion, smoking and driving habits," Pers. Individ. Dif., vol. 1, no. 3, pp. 197-206, (1980)

16. D. J. French, R. J. West, J. Elander, and J. M. Wilding, "Decision-making style, driving style, and self-reported involvement in road traffic accidents.," Ergonomics, vol. 36, no. 6, pp. 627-644, (1993)

17. E. Gulian, G. Matthews, A. I. Glendon, D. R. Davies, L. M. Debney, "Dimensions of driver stress," Ergonomics, vol. 32, no. 6, pp. 585-602, (1989)

18. H. Hooft van Huysduynen, J. Terken, J.-B. Martens, B. Eggen, "Measuring Driving Styles: A Validation of the Multidimensional Driving Style Inventory," in 7th International Conference on Automotive User Interfaces and Interactive Vehicluar Applications, (2015), pp. 257-264

19 M. Ishibashi, M. Okuwa, S. Doi, M. Akamatsu, "Indices for characterizing driving style and their relevance to car following behavior," Proc. SICE Annu. Conf., pp. 
1132-1137, (2007)

20. F. M. Poó, R. D. Ledesma, "A Study on the Relationship between Personality and Driving Styles," Traffic Inj. Prev., vol. 14, pp. 346-352, (2013)

21. T. Lajunen, A. Corry, H. Summala, L. Hartley, "Cross-Cultural Differences in Drivers' Self-assessments of Their Perceptual-motor and Safety Skills: Australians and Finns," Pers. Individ. Dif., vol. 24, no. 4, pp. 539-550, (1998)

22. M. Zuckerman, D. Michael Kuhlman, M. Joireman, H. Kraft, "Five robust questionnaire scale factors of personality without culture," Pers. Individ. Dif., vol. 12, no. 9, pp. 929-941, (1993)

23. J. M. Burger, H. M. Cooper, "The desirability of control," Motiv. Emot., vol. 3, no. 4, pp. 381-393, (1979)

24. A. Field, Discovering Statistics using SPSS. Third Edition. (2009)

25. B. Williams, T. Brown, A. Onsman, "Exploratory factor analysis : A five-step guide for novices," Australas. J. Paramadicine, vol. 8, no. 3, pp. 1-13, (2012)

26. J. Raubenheimer, "An item selection procedure to maximise scale reliability and validity," SA J. Ind. Psychol., vol. 30, no. 4, pp. 59-64, (2004)

27. B. a. Jonah, R. Thiessen, E. Au-Yeung, "Sensation seeking, risky driving and behavioral adaptation," Accid. Anal. Prev., vol. 33, no. 5, pp. 679-684, (2001)

28. G. Miller, O. Taubman-Ben-Ari, "Driving styles among young novice drivers-The contribution of parental driving styles and personal characteristics," Accid. Anal. Prev., vol. 42, no. 2, pp. 558-570, (2010)

29. C. Distefano, M. Zhu, and D. Mîndrilă, "Understanding and Using Factor Scores: Considerations for the Applied Researcher," Pract. Assessment, Res. Eval., vol. 14, no. 20, pp. 1-11, (2009)

30. Q. Shahab, J. Terken, and B. Eggen, "Development of a Questionnaire for Identifying Driver's Personal Values in Driving," in Proceedings of the 5th International Conference on Automotive User Interfaces and Interactive Vehicular Applications AutomotiveUI '13, (2013), pp. 202-208

31. O. Taubman-Ben-Ari and D. Yehiel, "Driving styles and their associations with personality and motivation," Accid. Anal. Prev., vol. 45, pp. 416-422, (2012)

32. T. Vaa, "From Gibson, Crooks to Damasio: The role of psychology in the development of driver behaviour models," Transp. Res. Part F Traffic Psychol. Behav., vol. 25, pp. 112-119, (2014)

33 B. a. Jonah, "Sensation seeking and risky driving: A review and synthesis of the literature," Accid. Anal. Prev., vol. 29, no. 5, pp. 651-665, (1997)

34. T. Lajunen, H. Summala, "Effects of driving experience, personality, driver's skill and safety orientation on speed regulation and accidents," Traffic Transp. Psychol. Theory Appl., pp. 283-294, (1997)

35. M. J. M. Sullman, A. N. Stephens, M. Yong, "Anger, aggression and road rage behaviour in Malaysian drivers," Transp. Res. Part F Traffic Psychol. Behav., vol. 29, pp. 70-82, (2015)

36. M. Sikkenk and J. Terken, "Rules of Conduct for Autonomous Vehicles," in Proceedings of the 7th International Conference on Automotive User Interfaces and Interactive Vehicular Applications, (2015), pp. 19-22

37. D. Dudley, "Google Self-Driving Car Perfect for Elderly Drivers - AARP," AARP, (2015). [Online]. Available: http://www.aarp.org/home-family/personaltechnology/info-2014/google-self-driving-car.html. [Accessed: 16-Feb-2016] 